\title{
УДК 617.539:616.711.1-007-089
}

Слънъко Е.И., Мохаммед Камель М.М. Ражаби

\section{Патогенетическая связь межу аномалией Киари и сирингомиелией}

\author{
Институт нейрохирургии им. акад. А.П. Ромоданова НАМН Украины, г. Киев
}

Введение. По данным литературы, сирингомиелию выявляют при аномалии Киари с частотой от 43 до $87 \%[1,2]$. Взаимосвязь между аномалией Киари и сирингомиелией специалисты обсуждают с 50-х годов прошлого столетия [3, 4]. Аномалия Киари представляет собой смещение миндалин мозжечка (эктопия) через большое затылочное отверстие до уровня $\mathrm{C}_{\mathrm{I}}$, иногда $-\mathrm{C}_{\mathrm{II}}-\mathrm{C}_{\mathrm{III}}$ позвонков. Многие авторы полагают, что это единственное патологическое состояние при такой патологии, в то же время существуют исследования, в которых утверждается, что первоначальной причиной является малый объем задней черепной ямки (ЗЧЯ), что обусловливает вытеснение миндалин мозжечка вниз через большое затылочное отверстие $[5,6]$. Однако аномалия Киари может быть не выраженной. Так, вариант, при котором миндалины мозжечка заполняют всю большую затылочную цистерну (малая цистерна — light cistern) и нарушают ликвороотток от отверстия Мажанди, описан под термином аномалия Киари-0 [7]. При этом варианте нет смещения миндалин мозжечка ниже большой затылочной цистерны, ликвороток в субарахноидальных пространствах спереди от ствола головного мозга также может быть частично сохранен. Отверстия Luschka, как правило, открыты, однако ликвороток из отверстия Мажанди нарушен вследствие плотно прилежащих друг к другу миндалин или арахноидальных сращений. Как правило, при таком виде аномалии сирингомиелитических кист нет [8, 9]. От того, на каком этапе или при какой степени смещения миндалин формируется сирингомиелия, зависит скорость ее прогрессирования $[10,11]$.

Несмотря на наличие многочисленных работ, касающихся аномалии Киари и сирингомиелии, спорными остаются вопросы: является ли малый объем ЗЧЯ причиной аномалии Киари; существует ли корреляция между размерами ЗЧЯ и степенью смещения миндалин мозжечка, а также между размерами ЗЧЯ, степенью смещения миндалин, с одной стороны, и размерами сирингомиелитической кисты,

Таблица 1. Распределение больных по полу и возрасту

\begin{tabular}{|c|c|c|c|c|}
\hline \multirow{2}{*}{$\begin{array}{c}\text { Возраст } \\
\text { больных, } \\
\text { лет }\end{array}$} & \multicolumn{4}{|c|}{ Число больных } \\
\cline { 2 - 5 } & \multicolumn{2}{|c|}{ мужчины } & \multicolumn{2}{|c|}{ женщины } \\
\hline $17-44$ & 18 & 54,5 & 33 & 38 \\
\hline $45-59$ & 14 & 42,5 & 48 & 55,2 \\
\hline $60-73$ & 1 & 3 & 6 & 6,8 \\
\hline Всего & 33 & 100 & 87 & 100 \\
\hline
\end{tabular}

с другой. Решение этих вопросов явилось целью данной работы.

Материалы и методы исследования. Изучены данные диагностики у 120 больных с мальформацией Киари, нарушением ликвороциркуляции на краниовертебральном уровне, сирингомиелией или без нее, которых лечили в клинике с 2000 по 2010 г. Возраст больных от 17 до 73 лет, женщин было 87, мужчин - 33. Больные распределены по возрасту и полу (табл. 1)

У мужчин различия по возрасту недостоверны $\left(\mathrm{t}_{0,05}=1,95, \mathrm{P}>0,05\right)$, у женщин преобладали пациентки среднего возраста — от 45 до 59 лет $\left(\mathrm{t}_{0,05}=3,23, \mathrm{P}<0,05\right)$. При оценке коррелятивного взаимодействия между возрастными градациями у мужчин и женщин установлено, что корреляция достоверна $\left(\chi^{2}=7,255\right)$.

Возраст пациентов исследуемой группы составил в среднем $(49,5 \pm 12,3)$ года, в том числе женщин — $(50,9 \pm 11)$ лет, мужчин - $(47,96 \pm 14,1)$ года. Возрастной состав мужчин был более вариабельным, самому молодому пациенту было 19 лет, самому старшему - 65 лет. Стандартная погрешность и отклонение во всей выборке больных составили соответственно 1,49 и 12,33 , медиана - 50 лет. По результатам статистической обработки с использованием критерия Стьюдента различия числа больных в приведенных возрастных группах недостоверны $(\mathrm{P}>0,05)$. Длительность заболевания от 6 мес до 20 лет, в среднем на момент обследования - 5 лет. Выделены 4 группы больных в зависимости от длительности заболевания на момент госпитализации в нейрохирургический стационар: до 1 года, 1-2 года, 3-5 лет, более 5 лет (табл. 2).

Всем пациентам проведена МРТ с использованием импульсных последовательностей спин-эхо (SE) и градиент-эхо (GE). Получали Т1- и Т2-взвешенные изображения в сагиттальной плоскости, а также Т1взвешенные изображения - в аксиальной плоскости. Использовали стандартные параметры при получении T1-взвешенных изображений (TR - 500 мс, TE $34 \mathrm{mc)}$ и при получении Т2-взвешенных изображений (TR - 2060 мс, TE - 210 мc). Дополнительно получали гипер-T2-взвешенные изображения (TR - 5000 мс) в сагиттальной плоскости. «Миелографрический» эффрект этих томограмм обеспечивал лучшую визуализацию ликворной системы головного мозга. Срезы получали в аксиальной, сагиттальной и корональной плоскостях. При определении морфометрических показателей на MPT использовали общепринятые способы измерения костей свода и основания черепа и структур головного мозга [12]. Для определения выраженности мальфор-

Таблица 2. Распределение пациентов разного пола в зависимости от длительности заболевания

\begin{tabular}{|c|c|c|c|c|c|c|c|c|}
\hline \multirow{3}{*}{ Пол } & \multicolumn{8}{|c|}{ Число наблюдений при длительности заболевания, лет } \\
\hline & \multicolumn{2}{|c|}{ до 1} & \multicolumn{2}{|c|}{$1-2$} & \multicolumn{2}{|c|}{$3-5$} & \multicolumn{2}{|c|}{ более 5} \\
\hline & абс. & $\%$ & абс. & $\%$ & абс. & $\%$ & абс. & $\%$ \\
\hline Мужчины & 4 & 33,3 & 3 & 17,6 & 11 & 28,2 & 14 & 27 \\
\hline Женщины & 8 & 66,7 & 14 & 82,4 & 28 & 71,8 & 38 & 73 \\
\hline Всего & 12 & 100 & 17 & 100 & 39 & 100 & 52 & 100 \\
\hline
\end{tabular}


мации Киари измеряли степень каудальной дислокации продолговатого мозга и миндалин мозжечка. Принимали во внимание наличие кинкинга и передней дефрормации продолговатого мозга скато-зубовидным комплексом. Параметры сирингомиелитических кист и их уровень определяли на сагиттальных срезах. Положение миндалин мозжечка оценивали путем проведения перпендикуляра от нижней точки миндалин до линии БЗО - прямой, соединяющей нижний край ската основной кости - базион (Б) и нижний край затылочной кости - опистион (O).

Ключевым моментом исследования было измерение объема ЗЧЯ, объема сирингомиелитических кист по данным MPT и определение степени дислокации миндалин мозжечка в большое затылочное отверстие. Объем оценивали на МРТ снимках ЗЧЯ, шейного и грудного отделов позвоночника путем их анализа с использованием разработанной нами математической программы.

Для определения объема ЗЧЯ применяли разработанную формулу: $\mathrm{V}=1 / 3 \mathrm{~S}\left(\mathrm{~b}+\mathrm{c}\left(\mathrm{a}^{2}+\mathrm{ae}+\mathrm{e}^{2}\right) / \mathrm{a}^{2}\right)$, где $\mathrm{S}=\pi \mathrm{ad} / 4$. Объем ЗЧЯ рассчитывали как сумму объемов двух усеченных конусов (puc. 1).

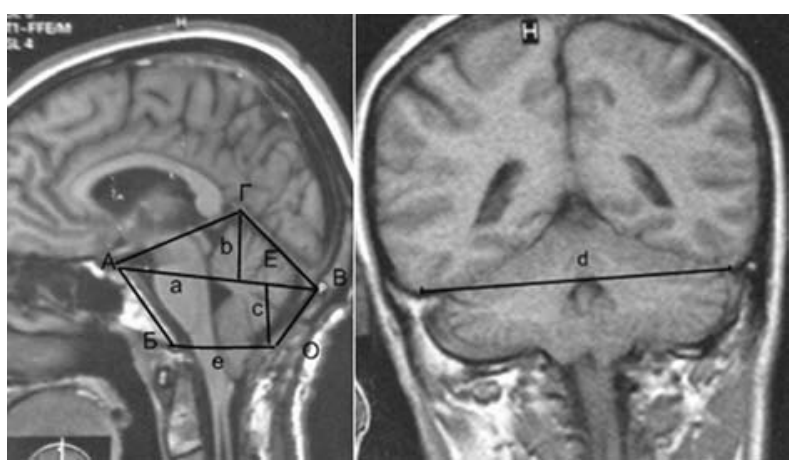

Puc. 1. Объем ЗЧЯ ограничен линией, соединяющей следующие ориентиры на срединно-сагиттальном срезе: базион (Б) - опистион (О) - внутренний затылочный выступ (В) - верхняя точка намета мозжечка (Г) — верхушка спинки турецкого седла $(\mathrm{A})$ - базион (Б).

Объем сирингомиелитических кист определяли по формуле эллипсоида: $\mathrm{V}=4 / 3 \pi \mathrm{abc}$ (где a, b, с - три радиуса эллипсоида: а — половина переднезаднего размера кисты на сагиттальных срезах; b - половина бокового размера кисты на фрронтальных срезах; с - половина протяженности кисты вдоль спинного мозга на сагиттальных срезах).

Для статистического анализа полученных результатов разработана стандартизованная база данных в програме Statistica 8 StatSoft, inc. 2007. Анализировали корреляционную взаимосвязь четырех показателей: объем ЗЧЯ, степень дислокации миндалин мозжечка ниже большого затылочного отверстия, объем сирингомиелитических кист, длительность заболевания до хирургического лечения.
Результаты и их обсуждение. Размеры ЗЧЯ в наших исследованиях от 110 до 218 см$^{3}$, в среднем $157,95 \mathrm{~cm}^{3}$. Статистическое отклонение составило 19,136. Размеры сирингомиелитической кисты от 2,51 до 98,44 $\mathrm{cm}^{3}$, в среднем 37,5545 см$^{3}$. Статистическое отклонение - 29,8697.

Степень дислокации миндалин мозжечка от 1,0 до 29,0 мм, в среднем 12,01 мм, статистическое отклонение - 6,29.

Длительность заболевания от 3 мес до 20 лет, в среднем 4,6 года. Статистическое отклонение - 4,21.

При проведении Spearman Rank корреляции (P<0,05) обнаружены следующие данные (maбл. 3).

По данным Spearman Rank корреляции - корреляция абсолютная - при коэффрициенте $\mathrm{R}=1$ и полностью отсутствует при $\mathrm{R}=0$. При наличии положительного коэффрициента $\mathrm{R}$ корреляция прямо пропорциональная, отрицательного $\mathrm{R}$ - обратно пропорциональна. Если переменная коррелирует сама с собой, корреляция, соответственно, равна 1.

Объем ЗЧЯ обратно пропорционально коррелирует с объемом сирингомиелитической кисты $(\mathrm{R}=-0,891415)$, степенью опущения миндалин $(\mathrm{R}=-0,863482)$, длительностью заболевания $(\mathrm{R}=-0,781014)$. Во всех трех корреляциях коэффрициент $\mathrm{R}$ приближается $\kappa 1$, что свидетельствует о ее высокой степени достоверности. Следовательно, чем меньше объем ЗЧЯ, тем больше степень дислокации миндалин мозжечка, размеры сирингомиелитической кисты и тем быстрее прогрессирует заболевание.

Соотношение на трехмерном графике объема ЗЧЯ, объема сирингомиелитической кисты и степени опущения миндалин представлено на рис. 2 .

Размеры ЗЧЯ у здоровых лиц варьируют от 140 до $230 \mathrm{~cm}^{3}$, в среднем $178 \mathrm{~cm}^{3}$. По данным волюметрических исследований, размеры ЗЧя у больных при аномалии Киари и сирингомиелии составляют от 126 до $162 \mathrm{~cm}^{3}$, в среднем $147 \mathrm{~cm}^{3}$ [12], различия по сравнению с показателями у здоровых лиц достоверны [13]. В настоящее время причиной возникновения и прогрессирования аномалии Киари считают малые размеры ЗЧЯ [14]. В то же время, соотношение размеров ЗЧЯ и степени смещения миндалин мозжечка, с одной стороны, и размерами сирингомиелитической кисты, с другой, не установлено [15, 16]. В наших исследованиях отмечена достоверная связь между размерами ЗЧЯ, степенью дислокации миндалин мозжечка, размерами сирингомиелитической полости и скоростью прогрессирования заболевания.

Полученные данные свидетельствуют, что, чем меньше размеры ЗЧЯ, тем больше степень дислокации миндалин мозжечка, размеры сирингомиелитической кисты и меньше длительность заболевания до проведения хирургического лечения с момента появления первых симптомов до развернутой клинической картины болезни.

Таблица 3. Spearman Rank корреляция показателей аномалии Киари

\begin{tabular}{|l|c|c|c|c|}
\hline \multicolumn{1}{|c|}{ Показатель } & Объем ЗЧя & объем кисты & $\begin{array}{c}\text { Степень опущения } \\
\text { миндалин }\end{array}$ & $\begin{array}{c}\text { Длительность } \\
\text { заболевания }\end{array}$ \\
\hline Объем ЗЧЯ & 1,000000 & $-0,891415$ & $-0,863482$ & $-0,781014$ \\
\hline Объем кисты & $-0,891415$ & 1,000000 & 0,878691 \\
\hline $\begin{array}{l}\text { Степень опущения } \\
\text { миндалин }\end{array}$ & $-0,863482$ & 0,878691 & 1,000000 \\
\hline $\begin{array}{l}\text { Длительность } \\
\text { заболевания }\end{array}$ & $-0,781014$ & 0,809382 & 0,802513 \\
\hline
\end{tabular}




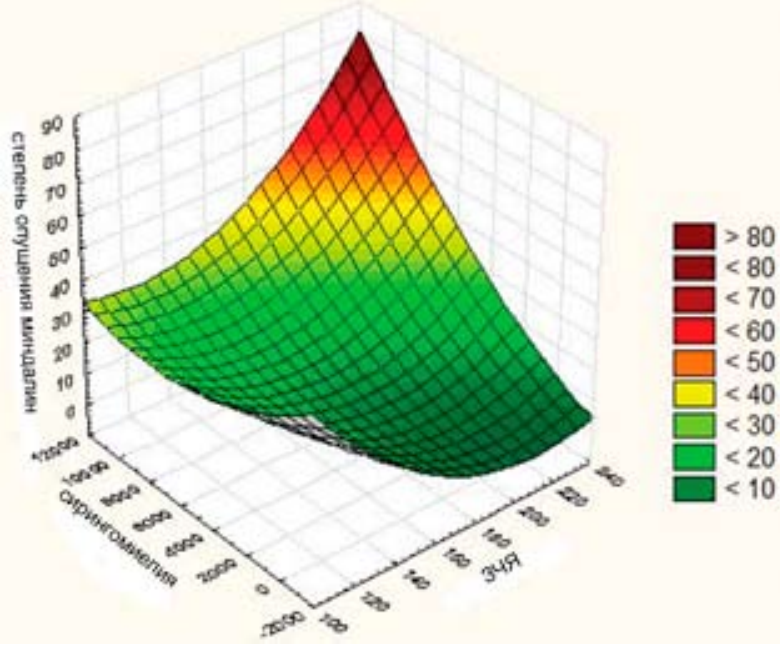

Puc. 2. Соотношение объема ЗЧЯ, объема сирингомиелитической кисты и степени опущения миндалин мозжечка до операции.

\section{Список литературы}

1. Chauvet D. Dura splitting decompression in Chiari type 1 malformation: clinical experience and radiological findings / D. Chauvet, A. Carpentier, B. George // Neurosurg. Rev. - 2009. - V.32, N4. - P.465-470.

2. Syringoperitoneal shunt in the treatment of syringomyelia / P. Kunert, M. Janowski, A. Zakrzewska [et al.] // Neurol. Neurochir. Pol. — 2009. - V.43, N3. - P.258-262.

3. Sindou M. Decompression for Chiari type I-malformation (with or without syringomyelia) by extreme lateral foramen magnum opening and expansile duraplasty with arachnoid preservation: comparison with other technical modalities (Literature review) / M. Sindou, E. Gimbert // Adv. Tech Stand. Neurosurg. - 2009. - V.34. - P.85-110.

4. Snyder P. Chiari malformation and syringomyelia / P. Snyder // Radiol. Technol. — 2008. - V.79, N6. — P.555-558.

5. Malformations of the craniocervical junction (Chiari type I and syringomyelia: classification, diagnosis and treatment) / A.A. Fernández, A.I. Guerrero, M. Martínez [et al.] // BMC Musculoskelet. Disord. — 2009. — V.17, N10. — Suppl.1. — S1.

6. Chiari type I malformation in a pediatric population / L.A Aitken, C.E. Lindan, S. Sidney [et al.] // Pediatr. Neurol - 2009. - V.40, N6. - P.449-454.

7. Brodbelt A.R. Syringomyelia and Chiari malformations. Quiz / A.R. Brodbelt // Br. J. Neurosurg. — 2009. — V.23, N1. - P.104-105.

8. Syringomyelia associated with Chiari I malformation / M Lucchetta, A. Cagnin, M. Calderone [et al.] // Neurol Sci - 2009. - V.30, N6. - P.525-526.

9. Incidence of basioccipital hypoplasia in Chiari malformation type I: comparative morphometric study of the posterior cranial fossa. Clinical article / R. Noudel, N. Jovenin, C. Eap [et al.] // J. Neurosurg. — 2009. — V.111, N5. - P.1046-1052.

10. Suboccipital craniotomy in the surgical treatment of Chiari I malformation / Y.C. Chou, R. Sarkar, F.C. Osuagwu [et al.] // Childs Nerv. Syst. — 2009. - V.25, N9. - P.1111-1114.

11. Struck A.F. Idiopathic syringomyelia: phase-contrast MR of cerebrospinal fluid flow dynamics at level of foramen magnum / A.F. Struck, V.M. Haughton // Radiology. — 2009. - V.253, N1. - P.184-190.

12. Sgouros S. Posterior fossa volume in children with Chiari malformation type I. / S. Sgouros, M. Kountouri, K. Natarajan // J. Neurosurg. - 2006. - V.105, N2 (suppl). - P.101-106.

13. Long-term follow-up of Chiari-related syringomyelia in adults: analysis of 157 surgically treated cases / N Aghakhani, F. Parker, P. David [et al.] // Neurosurgery. - 2009. - V.64, N2. - P.308-315.

14. Morphometric analysis of the craniocervical juncture in children with Chiari I malformation and concomitant syringobulbia / R.S. Tubbs, M. Bailey, W.C. Barrow [et al.] // Childs Nerv. Syst. - 2009. - V.25, N6. - P.689-692.

15. Effects of posterior fossa decompression with and withou duraplasty on Chiari malformation-associated hydromyelia / I. Munshi, D. Frim, R. Stine-Reyes [et al.] // Neurosurgery. - 2000. - V.46, N6. - P.1384-1389.

16. Association of HTLV-I with Arnold Chiari syndrome and syringomyelia / G.M. Viana, J.A. Diniz Neto, S. Furtado Ide [et al.] // Braz. J. Inf. Dis. — 2008. — V.12, N6. — P.536-537.

Одержано 17.05 .10

\title{
Слинъко С.І., Мохаммед Камель М.М. Ражабі
}

\section{Патогенетичний зв'язок між аномалією Кіарі і сирингомієлією}

\author{
Інститут нейрохірургії ім. акад. А.П. Ромоданова НАМН України, м. Київ
}

Мета роботи - вивчення кореляційних зв'язків між розмірами задньої черепної ямки, ступенем зміщення мигдаликів мозочка, розмірами сирингомієлітичної кісти, швидкістю прогресування захворювання.

Робота основана на аналізі діагностичних даних до і після операції у 120 хворих з мальформацією Кіарі, порушенням ліквороциркуляції на краніовертебральному рівні, сирингомієлією або без такої.

Отримані дані свідчать, що, чим менше розміри задньої черепної ямки, тим більше ступінь дислокації мигдаликів мозочка, розміри сирингомієлітичної кісти і менше тривалість захворювання до проведення хірургічного лікування.

Ключові слова: аномалія Кіарі, сирингомієлія, задня черепна ямка.

\section{Слънъко Е.И., Мохаммед Камель М.М. Ражаби}

\section{Патогенетическая связь между аномалией Киари и сирингомиелией}

\section{Институт нейрохирургии им. акад. А.П. Ромоданова НАМН Украины, г. Киев}

Цель работы - изучение корреляции между размерами задней черепной ямки, степенью смещения миндалин мозжечка, размерами сирингомиелитической кисты, скоростью прогрессирования заболевания.

Работа основана на анализе диагностических данных до и после операции у 120 больных с мальформацией Киари, нарушением ликвороциркуляции на краниовертебральном уровне, сирингомиелией или без нее.

Полученные данные свидетельствуют, что, чем меньше размеры задней черепной ямки, тем больше степень дислокации миндалин мозжечка, размеры сирингомиелитической кисты и меньше продолжительность заболевания до проведения хирургического лечения.

Ключевые слова: аномалия Киари, сирингомиелия, задняя черепная ялка. 


\section{Slynko E.I., Mohamed Kamel M.M. Ragabi}

\section{Pathogenic connection of Chiari anomaly and syringomyelia \\ Institute of Neurosurgery named after acad. A.P. Romodanov \\ of National Academy of Medical Sciences of Ukraine, Kiev}

The aim of this research — studying of correlation between posterior cranial fossa size and degree of cerebellar tonsils displacement, size of cyrix cysts, and speed of disease progression.

The research is based on diagnostic data analysis before and after surgery at 120 patients with Chiari malformation, liquor circulation disorders on craniovertebral level, with or without syringomyelia.

Received data suggest that the smaller size of the posterior cranial fossa is, the degree of cerebellar tonsils dislocation is greater, cyrix cysts are larger and disease duration is less before surgical treatment performing.

Key words: anomaly of Chiari, syringomyelia, posterior cranial fossa.

\section{Комментарий \\ к статье Слынько Е.И., Мохаммеда Камеля М.М. Ражаби «Патогенетическая сВязь межу аномалией Киари и сирингомиелией»}

Авторы осветили актуальную для спинальной нейрохирургии тему - соотношения аномалии Киари у взрослых и сирингомиелии. Для лечения аномалии Киари в мире применяют различные виды хирургических вмешательств, часто патогенетически необоснованных. Только после опубликования Gardner в 1965 г. гидродинамической теории большинство видов сирингомиелии стали связывать с аномалией Киари. Доказанность такой связи обсуждается. Однако причина дислокации миндалин мозжечка не установлена. Авторы измеряли объем задней черепной ямки, сирингомиелитических кист, степень дислокации миндалин мозжечка в большое затылочное отверстие. Объем оценивали на основании данных МРТ задней черепной ямки, шейного и грудного отделов позвоночника путем их анализа с применением

разработанной математической программы. Полученные данные свидетельствуют, что патогенетически первичной причиной возникновения аномалии Киари, а в дальнейшем - сирингомиелии являются малые размеры задней черепной ямки. На большом материале авторами доказано, что, чем меньше размеры задней черепной ямки, тем больше степень дислокации миндалин мозжечка, размеры сирингомиелитической кисты и меньше длительность заболевания до проведения хирургического лечения, т.е. с момента появления первых симптомов до развернутой клинической картины болезни. Эти важные данные обусловливают предполагаемую хирургическую технику лечения аномалии Киари и сирингомиелии - восстановление объема задней черепной ямки и большой затылочной цистерны.

H.A. Сапон, доктор мед. наук, cm. науч. сотр. отделения ВосстаноВительной нейрохирургии Института нейрохирургии им. акад. А.П. РомоданоВа НАМН Украины

\section{Комментарий \\ к статье Слынько Е.И., Мохаммеда Камеля М.М. Ражаби «Патогенетическая сВязь межу аномалией Киари и сирингомиелией»}

До внедрения магниторезонансной томограсрии и в ранний период ее использования мальформацию Киари считали раритетной патологией, что имело объективные причины: трудности клинической диагностики из-за полиморфности неврологических симптомов, инструментальной диагностики. Взаимосвязь между аномалией Киари и сирингомиелией обсуждается в литературе с 50-х годов прошлого столетия.

Авторы располагают клиническим опытом хирургического лечения 120 больных с аномалией Киари с сирингомиелией и без нее. Авторы изучили важные дискутабельные вопросы: является ли малый объем задней черепной ямки причиной аномалии Киари; существует ли корреляция между размерами задней черепной ямки, степенью смещения миндалин мозжечка и размерами сирингомиелитической кисты. Проведен анализ в зависимости от возраста, пола, длительности заболевания. Представляют интерес разработанные авторами формулы для измерения объема сирингомиелитической кисты и задней черепной ямки.

Приведены сведения о размерах задней черепной ямки и сирингомиелитической кисты.

Результаты свидетельствуют, что, чем меньше объем задней черепной ямки, тем больше степень дислокации миндалин мозжечка, размеры сирингомиелитической кисты и тем быстрее прогрессирует заболевание. 